\title{
Fundholding in general practice and financial risk
}

\author{
B J Crump, J E Cubbon, M F Drummond, R A Hawkes, M D Marchment
}

\begin{abstract}
Objective-To estimate the financial effect of random yearly variations in need for services on fundholding practices with various list sizes.

Design-A simulation model was derived using historical data on general practitioner referrals for the 113 surgical procedures covered by the general practitioner fund, combined with data on the hospital prices for those procedures.
\end{abstract}

Patients-Resident population of Central Birmingham Health Authority.

Main outcome measures-Expected expenditure on the relevant surgical procedures for the whole district and for practices with list sizes of 9000 , $12000,15000,18000,21000$, or 24000 for each of 100 simulated years.

Results-By using average hospital prices for the West Midlands region the mean (SD) annual expenditure for the 179400 residents was $£ 4832471$ ( $\$ 87$ 149); the random variation between the 5th and 95th most expensive years was $5 \cdot 7 \%$ of the mean cost. For a practice with a list size of 9000 the values were $\$ 244891$ ( $£ 18349$ ), with a variation of $27 \cdot 5 \%$. With a list size of 24000 the values were $\$ 652762$ (£32 512), with a variation of $15 \cdot 3 \%$.

Conclusions-Random variations in need for inpatient services will have a significant financial impact on the practice fund. The problem will be particularly great for smaller practices. Additional measures are required to ensure that the scheme is not undermined and that the potential benefits are secured.

Hearthent of Public

Birmingham Health

Authority, Edgbaston,

Birmingham B15 2TZ

B J Crump, MFCM, director of public health

$\mathrm{J} \mathrm{E}$ Cubbon, $\mathrm{MA}$, research and information officer

\section{Centre for Health}

Economics, University of

York, York

M F Drummond, DPHIL, professor

Tamworth, Staffordshire R A Hawkes, MB, general practitioner

Community and Mental Health Unit, South East Staffordshire Health Authority

M D Marchment, $\mathrm{MCDH}$, unit general manager

Correspondence to: Dr B J Crump, Department of Public Health Medicine, South Birmingham Health Authority, Birmingham

B15 2TZ.

$B M \gamma$ 1991;302:1582-4

9000 or more have been eligible to become fund size this entails the partners managing a financial allocation from which they can purchase certain specified services for their patients. The budgets for individual practices are set by using historical data from 1989-90 on referrals for the services concerned. When proposed this method of setting budgets stimulated considerable debate; of particular interest were the financial consequences of random variation in need for services from year to year and the minimum practice population size required to operate a fund successfully.

The fund covers four main types of expenditure: staff employed by the practice; drugs prescribed; outpatient care, including consultant consultations, treatment from members of the professions allied to medicine, and domiciliary visits; and inpatient care for a list of surgical procedures indicated by the Department of Health. ${ }^{2}$ When hospitals produced prices for these procedures we were able to estimate the impact of random variation in demand on the general practitioners' funds. We simulated the impact of random variation in need for hospital services on the element of the fund allocated for these services by using historical data on referrals.
Methods

Data from the West Midlands Regional Health Authority regional information system were obtained on all finished consultant episodes for residents of Central Birmingham Health Authority for the year from 1 April 1989 to 31 March 1990. A computer program identified those elective episodes which included one of the 113 surgical procedures listed by the Department of Health to be covered by general practitioners' funds.

For a proportion of episodes the information system showed no recorded diagnostic or operative codes. We assumed that no systematic bias had operated which would lead to a tendency to fail to code episodes which included the relevant operations at a different rate from episodes that did not. Therefore, the number of episodes identified was increased in a pro rata fashion.

We assumed that the number of operations a year carried out in a population has a Poisson distribution. The best estimate of the mean number of operations in Central Birmingham Health Authority $(\mathbf{P})$ was the number identified by the program, adjusted for uncoded episodes. This value estimate represented both the mean of the distribution and its variance. If the mean was above 30 the distribution could be approximated by the normal distribution.

Normally distributed random numbers with a mean of zero and standard deviation of 1 were then generated by using the formulas: $a_{1}=V-2 \ln R_{1} \cos \left(2 \pi R_{2}\right)$ and
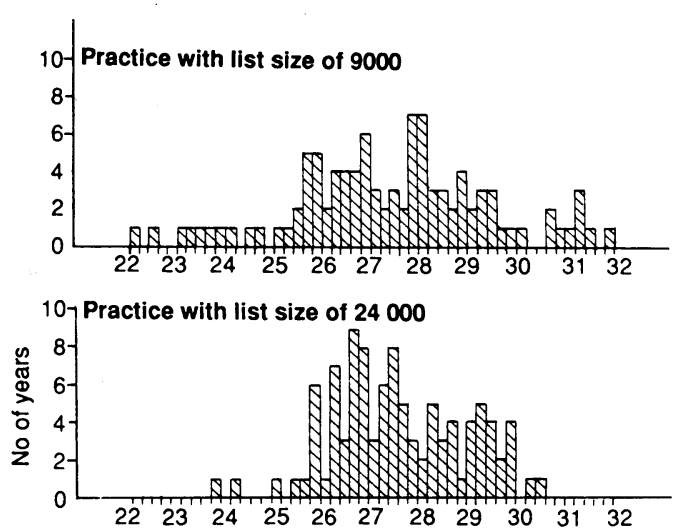

18 Total population of Central Birmingham Health Authority

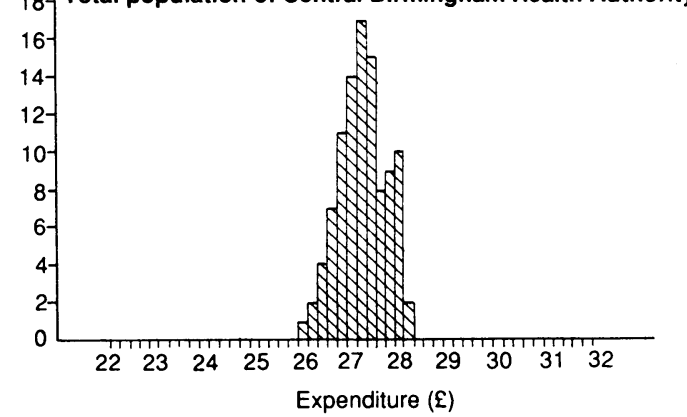

Frequency distribution of per caput expenditure for 100 simulated years 
$a_{2}=V-2 \ln R_{2} \sin \left(\pi R_{1}\right)$, where $R_{1}$ and $R_{2}$ are a pair of $[0,1]$ random numbers. Two normally distributed sets of random numbers $\left(b_{1}\right.$ and $\left.b_{2}\right)$ with mean $P$ and standard deviation $\sqrt{ } \mathbf{P}$ were then derived from the formulas: $b_{1}=\mathbf{P}+\sqrt{\mathrm{Pa}_{1}}$ and $\mathrm{b}_{2}=\mathbf{P}+\sqrt{\mathrm{Pa}_{2}}$. In this way the number of relevant operations carried out on residents of Central Birmingham Health Authority for 100 random years was simulated.

Each operation was assigned to one of the specific procedures according to the actual distribution of cases across the 113 operations during 1989-90. For example, $0.05 \%$ of the procedures carried out during $1989-90$ were orchidopexies. We therefore assumed that each simulated case would have a $0.05 \%$ probability of being an orchidopexy. A list of the mean price for each procedure was obtained from the West Midlands Regional Health Authority. From this list each case that would have occurred during each simulated year was assigned the relevant price. The total expenditure during each of the 100 simulated years was obtained by summing the expenditures for each of the procedures.

Central Birmingham Health Authority had a population of 179400 in 1989-90. To estimate the effects of random variation for practices with populations of differing sizes the above simulation was carried out with a mean number of annual procedures $\left(\mathrm{P}_{\mathrm{N}}\right)$ of $\mathrm{P} \times(\mathrm{N} / 179400)$, where $\mathrm{N}$ was the size of the practice list.

\section{Results}

The dataset obtained from the regional information service showed 33453 inpatient finished consultant episodes for the residents of Central Birmingham Health Authority for the financial year 1989-90. Of these $4577(13.7 \%)$ had no diagnosis or operation recorded. The computer program identified 5240 episodes in which one of the relevant surgical procedures was performed. Hence 5240 of the 28896 (33453-4557) coded episodes $(18 \cdot 1 \%)$ related to a procedure that would be funded by fundholding general practitioners. When adjusted for uncoded episodes the total number of procedures that would be funded by general practitioners $(\mathrm{P})$ was 6071 . For a practice of $9000 \mathrm{P}_{9000}$ was $305 ; \mathrm{P}_{\mathrm{N}}$ increased with increasing list size so that for a list of $24000 \mathrm{P}_{24000}$ was 812.

The table summarises the results of the simulation. The mean total expenditure for episodes including the relevant operations for the total population of the health authority was $£ 4832471(\mathrm{SD}=87149)$. The random variation was such that the cost of the 95th most expensive simulated year exceeded that of the fifth most expensive by $£ 275070$, or $5 \cdot 7 \%$ of the mean cost.

The estimated mean total expenditure of inpatient treatment for a practice with list size of 9000 was $£ 244891$. By using the same measure of variation as for the total population the annual costs were much less stable for a practice of this size, with variation of $27 \cdot 5 \%$

Simulations of total costs $(£)$ of general practitioner funded operations for practices of various list sizes in Central Birmingham Health Authority

\begin{tabular}{lcccrrrr}
\hline & & \multicolumn{7}{c}{ Practice sizes } \\
\cline { 3 - 8 } $\begin{array}{l}\text { Simulated years } \\
\text { (*rcording to cost) }\end{array}$ & $\begin{array}{c}\text { Whole } \\
\text { population }\end{array}$ & 9000 & 12000 & 15000 & 18000 & 21000 & 24000 \\
\hline Minimum & 4621252 & 197145 & 274504 & 340146 & 434527 & 481576 & 564956 \\
5th Centile & 4689312 & 211450 & 291445 & 358200 & 439177 & 517088 & 607929 \\
25th Centile & 4772657 & 233390 & 307796 & 386637 & 466132 & 548310 & 629688 \\
Median & 4835794 & 245086 & 320531 & 401703 & 483093 & 568453 & 649247 \\
$\quad 75$ th Centile & 4904961 & 256878 & 334934 & 414991 & 506050 & 588983 & 679108 \\
95th Centile & 4964382 & 278677 & 360146 & 445318 & 527195 & 605915 & 707844 \\
Maximum & 5011072 & 284703 & 369007 & 459177 & 555296 & 636888 & 722055 \\
Mean & 4832471 & 244891 & 321121 & 402308 & 485270 & 567201 & 652762 \\
SD & 87149 & 18349 & 19734 & 24686 & 27353 & 28415 & 32512 \\
\% Variation & $5 \cdot 7$ & 27.5 & $21 \cdot 4$ & $21 \cdot 7$ & $18 \cdot 1$ & $15 \cdot 7$ & $15 \cdot 3$ \\
\hline
\end{tabular}

of the mean cost between the fifth and 95th most expensive years. Indeed, the cost in the most expensive year exceeded that of the least expensive by $£ 87558$, $35.8 \%$ of the mean cost. This means that, at worst, a practice could be $17 \cdot 9 \%$ over or under budget in a given year. For a practice of this size in 39 of the 100 years expenditure exceeded the mean by more than $1 \%$, the amount of revenue expenditure that health authorities are allowed to carry forward from year to year.

The simulated results showed a reduction in variation as practice size increased. With a large practice of 24000 patients the cost of the 95 th most expensive year exceeded that of the fifth most expensive by $£ 99915$, $15 \cdot 3 \%$ of the mean annual cost.

The figure shows variability, expressed as the per caput expenditure for each of the 100 simulated years. Values are shown for the population of the health authority and for the smallest and largest practice sizes studied.

\section{Discussion}

By simulation we have estimated the effect of random variation in service need on the component of a general practice's fund allocated to inpatient treatment. The principal finding-that the variation is much greater for a relatively small practice size-will come as no surprise. However, we are unaware of any previous attempts to quantify this variation by using data on referrals from a real patient population and published NHS hospital prices.

The figures represent only those variations in expenditure which can be expected as a result of random variations in the number of referrals. Because we used the mean regional price for each procedure other variations due to price differences between hospitals have not been accounted for. This was deliberate because patients from a particular practice would tend to be referred to a more limited range of hospitals than those in the whole district. Also, it is possible that fundholding general practitioners could search for low prices to keep within their budget. While there are reports of some fundholding practices negotiating better deals for their patients ${ }^{3}$ many district health authorities have included clauses in contracts to prevent their residents from being disadvantaged. None the less, price variations between hospitals in the west midlands are considerable, with hospitals apparently using the same costing methodology quoting prices that vary more than 10 -fold for the same procedure.

We excluded from our analysis finished consultant episodes in which the patient was admitted as an emergency, as the cost for these patients will not fall on the general practitioner's fund. One course of action open to a general practitioner during a year in which service need, through chance, seems to be high, will be not to refer patients for elective surgery, at least until he or she is confident about the state of the budget. This may lead to a fall in waiting lists as seen from the hospital derived data, while fundholding practices hold their own list of patients waiting for referral.

The large financial effect of random variation is of concern because one of the features of the fundholding scheme is that practices are allowed to redeploy savings to improve the range or quality of services. Given the random variation, it will be difficult for a practice to know whether lower spending in a given year is the result of prudent use of resources or not; general practitioners may therefore be reticent about committing funds to improvement of services.

Several methods could be used to counteract the financial effect of random variation in service need. Firstly, the Department of Health has already introduced a ceiling of $£ 5000$ on the expenditure for any 
individual patient, with the district health authority paying for care costing more than this. The importance of this safeguard could not be assessed in our simulation as there was no easy way of linking the finished consultant episodes to individual patients. However, because none of the 113 surgical procedures has a mean price higher than $£ 5000$ in the west midlands, and 100 have a price lower than $£ 2000$, multiple admissions for operations would be required to exceed the limit and thus the safeguard is more likely to be relevant for patients with long term illnesses requiring repeated surgery.

Secondly, the Department of Health could allow fundholding practices considerable virement in the amount of underspending or overspending to be carried forward from year to year. As mentioned above, this would have to be greater than that allowed for district health authorities to date. If too much virement is allowed, however, practices may be less likely to use savings on the fund in a given year to improve the range or quality of services offered if they fear that a random variation in a future year may lead to significant overspending. If this happened it would undermine one of the largest potential benefits of general practitioner fundholding.

Thirdly, practices could be encouraged to pool their financial risk by joining together in consortiums. Alternatively they could contribute to a contingency reserve to be held by the regional health authority. This would be similar to the scheme currently used by districts to cope with medical negligence claims.

Finally, the ultimate security for potential fundholders is that they can stop participating in the scheme whenever they wish. As this may be perceived as a failure of the scheme, there may be a temptation to set funds at a level that would cushion the financial effect of random variation; but this would mean that the resources available to other services operated by the district health authority would be diminished because the general practitioner funds are deducted from the district's financial allocation.

We have previously pointed out that general practitioner fundholding embodies a complex array of benefits and risks. ${ }^{4}$ By simulating 100 years of general practitioner fundholding by using historical data on referrals and newly available hospital prices we have quantified the financial effect of random variations in service need for practices eligible for fundholding. We conclude that the financial impact is sufficiently great to be of concern to fundholding general practitioners and their patients. Additional measures are needed to ensure that the scheme is not undermined and that the potential benefits are secured.

I Smith R. Words from the source: an interview with Alain Enthoven. $B M J$ 1989;298:1166-8.

2 Department of Health. Funding general practice. London: $\mathrm{DoH}, 1989$

3 Hall C. Hospital to begin two-tier service. Independent 1991 May 3:2.

4 Drummond MF, Crump BJ, Hawkes A, Marchment MD. General practice fundholding. BMF 1990;301:1288-9.

(Accepted 25 April 1991)

\title{
The Future of General Practice
}

\section{Out of hours work in general practice}

\author{
Steve Iliffe, Ursula Haug
}

General practice is a demanding job in which the subjective experience of stress is associated with lack of mental wellbeing, marital problems, and alcohol abuse. ${ }^{1.3}$ Out of hours calls are a particular source of stress, especially night calls, ${ }^{4}$ and older general practitioners report more difficulties with out of hours work than do younger principals. ${ }^{5}$ General practitioners have described out of hours calls as being consultations that are diagnostically demanding ${ }^{6}$ and occur at a time when they are tired and prone to cope with rather than deal with problems. ${ }^{4}$ Misjudgment can be serious for doctor and patient; physical violence against general practitioners occurs more frequently on out of hours calls than at any other time.?

Most out of hours calls are from parents about their children. ${ }^{8}$ They may reflect parental inexperience, lack of social support driving parents to seek professional help urgently, ${ }^{10}$ or maladaptive behaviour transmitted as a family tradition. ${ }^{11}$ Elderly people are the second most frequent callers and are taken more seriously by their general practitioner than are anxious parents. ${ }^{8}$ Social class may be an important determinant of frequency of calls,${ }^{8}$ but some evidence suggests that although working class people value house visits more than do the middle class, they request them less often. ${ }^{12}$ Nevertheless, deprived inner city areas tend to have high rates of out of hours visits. ${ }^{813}$

\section{Deputising services}

It is hardly surprising that general practitioners are tending to reduce their hours of personal availability, mainly by transferring responsibility for night calls to deputies. ${ }^{14}$ Though groups of general practitioners provide most out of hours care through crosscover within or between practices, commercial deputising services are used by a growing proportion of genera practitioners, with $45 \%$ of practitioners nationally, ${ }^{15}$ $67 \%$ of a selected sample in London, ${ }^{4}$ and over $90 \%$ in Manchester ${ }^{8}$ making some use of commercial deputising services. The greatest obstacle to wider use of deputising services is probably not professional antipathy but the absence of commercial services outside urban areas.

Nevertheless, there has been much discussion about the merits and demerits of commercial deputising services, and the new contract for general practitioners has attempted to limit the transfer of out of hours work to deputies by financially rewarding doctors for doing their own night calls. ${ }^{16}$ The clinical quality of the care provided by commercial deputising services is difficult to assess, but studies of patient satisfaction with out of hours cover in general and by deputising services have shown that $70-80 \%$ of people seen by deputising service doctors are satisfied with the service they receive, ${ }^{151718}$ similar to the overall public satisfaction with NHS general practitioner services and rather better than that with hospital services. ${ }^{19}$ Satisfaction tends to be highest among older people and lowtst among the parents of young children, ${ }^{818}$ perhaps reflecting the seriousness with which the general practitioners treated their calls.

\section{Increase in demand}

The number of night calls nearly trebled between 1967 and 1976, ${ }^{20}$ and good reasons exist for thinking that the out of hours workload may continue to 